\title{
Microbial endoliths in skeletons of live and dead corals: Porites lobata (Moorea, French Polynesia)
}

\author{
T. Le Campion-Alsumard ${ }^{1}$, S. Golubic ${ }^{2}$, P. Hutchings ${ }^{3}$ \\ ${ }^{1}$ Centre d'Océanologie de Marseille, Université d'Aix Marseille II, URA CNRS 41, Station Marine d'Endoume, \\ F-13007 Marseille, France; and Antenne du Muséum et de l'EPHE, Moorea, BP 1013, French Polynesia \\ ${ }^{2}$ Biological Science Center, Boston University, 5 Cummington Street, Boston, Massachusetts 02215, USA \\ ${ }^{3}$ The Australian Museum, PO Box A285, Sydney South, New South Wales 2000, Australia
}

\begin{abstract}
Carbonate skeletons of hermatypic corals harbor diverse populations of microboring organisms. The assemblages of euendolithic (boring) algae and cyanobacteria inhabiting the corallum of live corals are different from those that colonize dead and denuded coral skeletons. The species composition of endoliths in live corals is a result of a selection in favor of oligophotic, positively phototropic, fast-growing taxa which can cope with the accretion rates of coral skeleton. Following the death and denudation of corals, the bioerosion of their skeletons changed profoundly with respect to (1) species composition of dominant endolithic microorganisms, (2) their boring patterns and (3) the direction of microboring activity. Skeletons of live colonies of Porites lobata were bored from the inside outward by the siphonalean chlorophyte Ostreobium quekettii. Dead and denuded parts of coral skeleton were colonized at the surface and bored inward by a succession of euendoliths, starting with colonization of the short-lived opportunistic pioneer endolith Phaeophila dendroides (Chlorophyta), followed by Mastigocoleus testarum and Plectonema terebrans (cyanobacteria), to establish within 2 yr a stable $O$. quekettii-dominated endolith community. The sequence of colonization and successional changes was determined using experimentally exposed carbonate substrates. During the life of the coral, the endoliths are protected from grazers. Their bioerosive activity keeps pace with the rate of coral accretion but avoids the skeletal surface adjacent to the coral tissue. The green bands formed by endoliths within the skeleton of live corals bear relevance to sclerochronological interpretations. Their formation reflects either variation in coral growth rates or algal seasonality, but most likely a combination of both. Endoliths in dead coral skeletons are exposed to grazing by mollusks, echinoderms and scarid fish, which significantly increases overall bioerosion rates. In the absence of intensive grazing, dead parts of coral skeleton are overgrown by epilithic algal turf. The series of successional biological changes triggered by the death and denudation of corals shifts the ecological balance between constructive and destructive forces on a coral reef in favor of the latter.
\end{abstract}

KEY WORDS: Bioerosion - Corals - Endoliths - Euendoliths - Microborers · Algae - Cyanobacteria * French Polynesia · Grazers · Ostreobium · Sclerochronology

\section{INTRODUCTION}

A sensitive balance between constructive and destructive forces is required for the maintenance and persistence of coral reefs (Hubbard et al. 1990). Some organisms, such as corals and calcareous algae that deposit skeletal calcium carbonate, build and fortify the reef architecture. Other organisms break down this carbonate substrate by chemical (boring by dissolution) or mechanical (scraping) means. Chemical disso- lution of carbonate substrates by organisms is called 'biocorrosion', and mechanical destruction 'bioabrasion': biocorrosion contributes to carbon cycling by releasing $\mathrm{CO}_{2}$ into solution, while bioabrasion adds to the production of fine-grain bioclastic sediments (Schneider \& Torunski 1983). Any combination, interaction, and cumulative effect of these activities can be defined as bioerosion (Neumann 1968). These activities have geochemical and sedimentological importance. Biogenic destruction of carbonate sub- 
strates is carried out by a variety of organisms, including microborers (cyanobacteria, algae, fungi, microinvertebrates), macroborers (e.g. sponges, bivalves, cirripedia, polychetes), and grazers (gastropods, echinoderms, scarid fish).

In recent years, studies of bioerosion of coral reefs have concentrated mainly on the activities of macroboring organisms (see Hutchings 1986 for review), whereas studies by Bak (1976), Kiene $(1985,1988)$, and Kiene \& Hutchings (1994) have emphasized the importance of grazing as a major agent of bioerosion in tropical habitats. Because microbial endoliths constitute a major food source for grazing animals, their distribution, dynamics of their settlement, and their response to grazing pressure are important factors in determining rates of grazing.

Coral skeletons are the most common substrate for euendoliths (sensu Golubic et al. 1981) on the reef. However, skeletons of live and dead corals are attacked by different microbial assemblages. Duerden (1902) identified the chlorophyte Ostreobium as the major endolithic constituent of live corals. Ostreobium was found to be responsible for the formation of conspicuous green bands running beneath and parallel to the polyp zone. In addition to Ostreobium, only the cyanobacterium Plectonema terebrans Bornet et Flahault (Lukas 1969, 1974), conchocelis stages of red algae (Laborel \& Le Campion-Alsumard 1979), and fungi (Kendrick et al. 1982, Bak \& Laane 1987) have been encountered within live coral skeletons. A different and more diverse endolithic assemblage has been described from skeletons of dead corals, and included Gomontia, Mastigocoleus, Plectonema and Hyella, in addition to Ostreobium (Weber van Bosse 1932). The causes of these differences, as well as the assessment of the significance of endolith contribution to coral growth and bioerosion, have been the subject of much controversy (see Highsmith 1981 for review, Delvoye 1992).

In publications dealing with French Polynesia, endolithic cyanobacteria have been included in published species lists, without their ecological roles being addressed (Newhouse 1954). Ranson $(1955,1956)$ discussed the roles played by algae and invertebrates in the dissolution of limestone in Touamotu Archipelago, mentioning Hyella sp., Ostreobium sp. and Entophysalis granulosa. Payri (1987) included endolithic organisms in measurements of primary production of reefs, without dealing with their taxonomic identity and diversity.

The present study reports on the successional changes in phototrophic microbial endolith assemblages following damage and death of corals on the Pacific volcanic island Moorea, near Tahiti, French
Polynesia, and discusses the relevance of green band formation to sclerochronology.

\section{MATERIALS AND METHODS}

Study area. The study was carried out on the Moorea reef complex. The island of Moorea is located some $20 \mathrm{~km}$ from Tahiti at $17^{\circ} 30^{\prime} \mathrm{S}, 149^{\circ} 50^{\prime} \mathrm{W}$. It is a high volcanic island surrounded by a fringing reef and a barrier reef. The samples were collected on a transect across the Tiahura barrier reef flat (Fig. 1) in a shallow, lagoonal, permanently submerged environment. This is a bionomically well-documented area where many bioerosion studies have been conducted (Hutchings \& Peyrot-Clausade 1988, Peyrot-Clausade et al. 1992, Gattuso et al. 1993).

Sample preparation. We studied microbial endoliths in massive skeletons of live and dead corals. Small chips of coral skeleton (ca $5 \mathrm{~mm}$ diameter) with associated coral tissue and endoliths were collected and submitted to different preparation methods:

(1) Samples were fixed in a buffered 2 to $3 \%$ formaldehyde solution in sea water. Preparations for light microscopy were made by dissolving the carbonate substrate with Perenyi solution $(0.5 \%$ chromic acid, $10 \%$ nitric acid, 70 to $90 \%$ alcohol, in the relations $3: 4: 3$ ). The extracted endoliths were mounted on slides and observed by light microscopy.

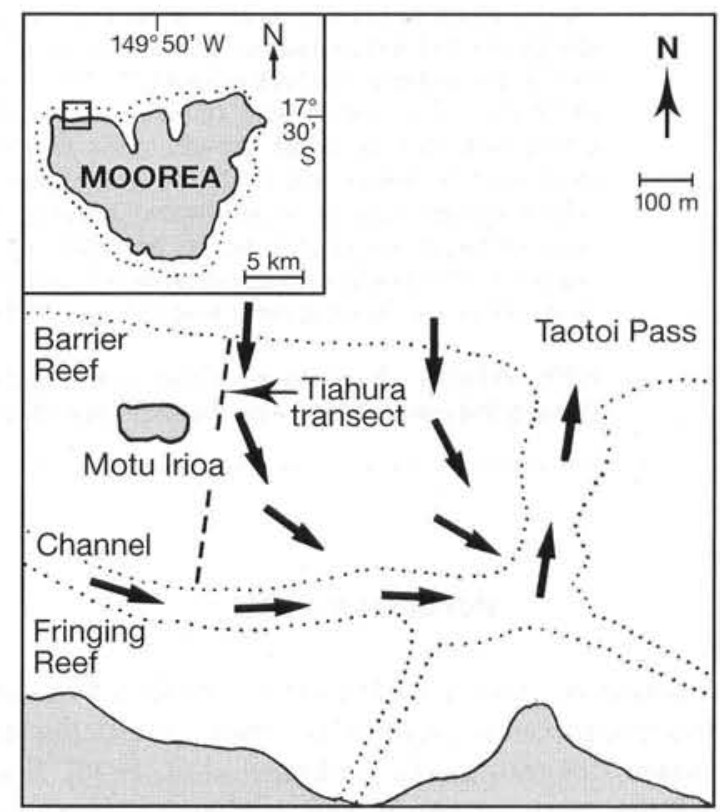

Fig. 1. The study site at Tiahura transect on the NE coast of the high volcanic island of Moorea (inset), near Tahiti, French Polynesia. Arrows indicate direction of current flow. Modified from Gattuso et al. (1993) 
(2) Mineral matter, such as carbonate coral skeleton, was cleaned of organic matter using concentrated sodium hypochlorite solution (Clorox household bleach, Eau de Javel), and observed using scanning electron microscopy (SEM).

(3) A selection of samples was fixed with $2.5 \%$ glutaraldehyde in sea water and cacodylate buffer $(20 \mathrm{~h}$, $\mathrm{pH}$ adjusted to 8 ), postfixed in $2 \%$ osmium tetroxide in sea water $(2 \mathrm{~h})$, and then gradually dehydrated (alcohol series). These were prepared for different purposes: (3.1) For the in situ study of endoliths, the dehydrated samples were freeze-fractured in liquid nitrogen, or critical-point-dried, and observed with SEM. (3.2) Other dehydrated samples were embedded in Durcupan Araldite, starting with an LMR-SOL/Durcupan mixture (LMR = trichlorethane) according to the modified method of Golubic et al. (1970). Following embedding, the samples were cured for 48 to $72 \mathrm{~h}$ at $60^{\circ} \mathrm{C}$. The hardened blocks were cut, and (3.2.1) petrographic thin sections were prepared for light microscopy. In such preparations, microboring organisms can be observed in relation to the surrounding carbonate substrate. (3.2.2) Other cut blocks and oriented sections were exposed briefly to Perenyi solution and partially etched to expose the resin-cast microborings. These were observed by SEM in the context of the bored substrate. (3.2.3) Horizontal distribution of endoliths was studied by SEM after complete dissolution of substrate and exposure of endolith casts. (3.2.4) Selected cut and acid-treated blocks were re-embedded in Araldite. Oriented thick and thin sections were prepared for identifying the microorganisms in situ. These preparations were suitable for examination by light microscopy and transmission electron microscopy.

Quantitative evaluation of microboring activity. Density of endolithic populations was determined from oriented re-embedded sections by direct counting under the microscope. The density was calculated for a unit area of $1 \mathrm{~mm}^{2}$. Computer-aided image analysis of photomicrographs taken by light microscopy and SEM was used to obtain an integrated average percentage of the substrate removed by microorganisms. High concentrations of endoliths in colored bands were evaluated using low power microscopy of partially etched sections through coral heads.

Exposure experiments. The successional patterns of substrate colonization by microborers were studied by exposure experiments in the field. Cleanly cut blocks made of Porites lobata coral skeleton were affixed with marine cement to large $P$. lobata colonies on the Tiahura barrier reef. The exposed substrates were sampled at increasing time intervals of up to 3 mo over a period of $2 \mathrm{yr}$, and examined for endolithic colonizers. A parallel set of blocks of calcite spar was exposed for comparison.

\section{RESULTS}

\section{Microbial boring in skeletons of live corals}

The endolithic microflora in skeletons of live Porites lobata colonies consists almost exclusively of the siphonalean chlorophyte Ostreobium quekettii, accompanied only by small septate fungal hyphae. In this respect, $P$. lobata is similar to live corals of other species in the study area (Le Campion-Alsumard unpubl.).

Filaments of Ostreobium quekettii extracted by dissolution of the skeleton were of variable size. They branched repeatedly into finer and finer ramifications, down to a size of $2 \mu \mathrm{m}$ diameter. These fine branches often meandered through the substrate, forming networks of various densities. The filaments were nonseptate, characterized by wall thickenings and knobby surface irregularities (Fig. 2). Their external morphology (Fig. 2 inset) is accurately reflected in the outlines of tunnels that $O$. quekettii leaves within the coral skeleton, which are here visualized by SEM of tunnel replicas cast in polymerizing resin.

The growth of Ostreobium quekettii was studied in oriented petrographic thin sections. O. quekettii grew continuously behind the depositional front of the coral

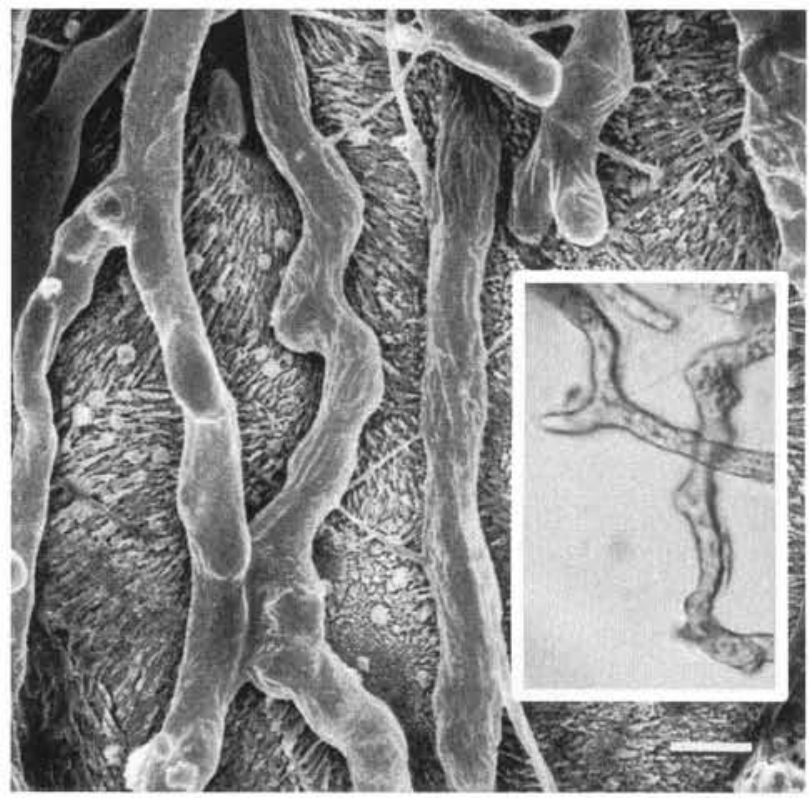

Fig. 2. Ostreobium quekettii (Siphonales, Chlorophyta), a ubiquitous microborer in skeletons of live corals. Shown are resin casts of $O$. quekettii borings in the skeleton of live Porites lobata exposed in a partially etched preparation. Typical knobby appearance of the filaments (inset) is recognizable in the cast outlines. Arrangements of aragonite grains of the corallum are seen in the background. Inset: Distal branches of $O$. quekettii filaments extracted by dissolution of carbonate. Same magnification; scale bar $=10 \mu \mathrm{m}$ 
skeleton, in the same general direction, effectively keeping pace with skeletal accretion by the polyps. Individual $O$. quekettii borings often reached the tips of newly formed skeletal spines (Le CampionAlsumard et al. 1995: this issue). O. quekettii filaments are euendolithic, i.e. penetrating and residing within the skeletal carbonate. $O$. quekettii did not penetrate the surface and exit the coral skeleton adjacent to the live coral polyps, although it has been observed to transgress uninhabited skeletal pores (Schroeder 1972). Following removal of healthy polyp tissue with Clorox bleach, the surface of the coral skeleton always appeared intact when viewed under SEM (Fig. 3a).

The polyps of Porites lobata occupy a relatively thick, 4 to $5 \mathrm{~mm}$ wide top layer of the corallum. Since Ostreobium quekettii penetrates all the way up to the depositional front of the corallum, it grows parallel to the polyps, rather than several mm below them, as is often reported. Only when the density of the $O$. quekettii network increases toward the interior (uninhabited) parts of the skeleton does it become visible to the unaided eye as a green band that extends 1 to $5 \mathrm{~mm}$ below the polyp zone. A 'pale' zone is usually seen in between. The green band is comprised of a dense growth of branched $O$. quekettii filaments loaded with chloroplasts and starch grains. In such areas of high filament concentration, over $25 \%$ of skeletal carbonate could be dissolved and removed by boring (Fig. 4). The lateral spreading of the green band extended parallel to that of the polyp zone, approaching it toward the outer slopes of coral heads. In corals with irregular, bumpy growth, increased color intensity of the band of endolithic algae correlated with depressions between faster-growing bumps. In these locations the band also moved closer to the coral surface.

Additional green or gray bands were observed deeper within the corallum. These older bands were also comprised of Ostreobium quekettii filaments which were mostly moribund and often changed to dark brown or black in color. However, O. quekettii filaments were not restricted to color bands. They extended throughout the corallum and connected the bands, showing variable density and chloroplast content (see also Lukas 1974).

\section{Microbial boring in dead coral skeletons}

Permanent damage of corals results in death of polyps and denudation of coral skeleton. Dead and denuded portions of coral skeletons were colonized by a microflora which differed from that in live coral skeletons. These endoliths penetrated coral skeletons from the surface down into the substrate, in a general direction opposite to that of Ostreobium quekettii in
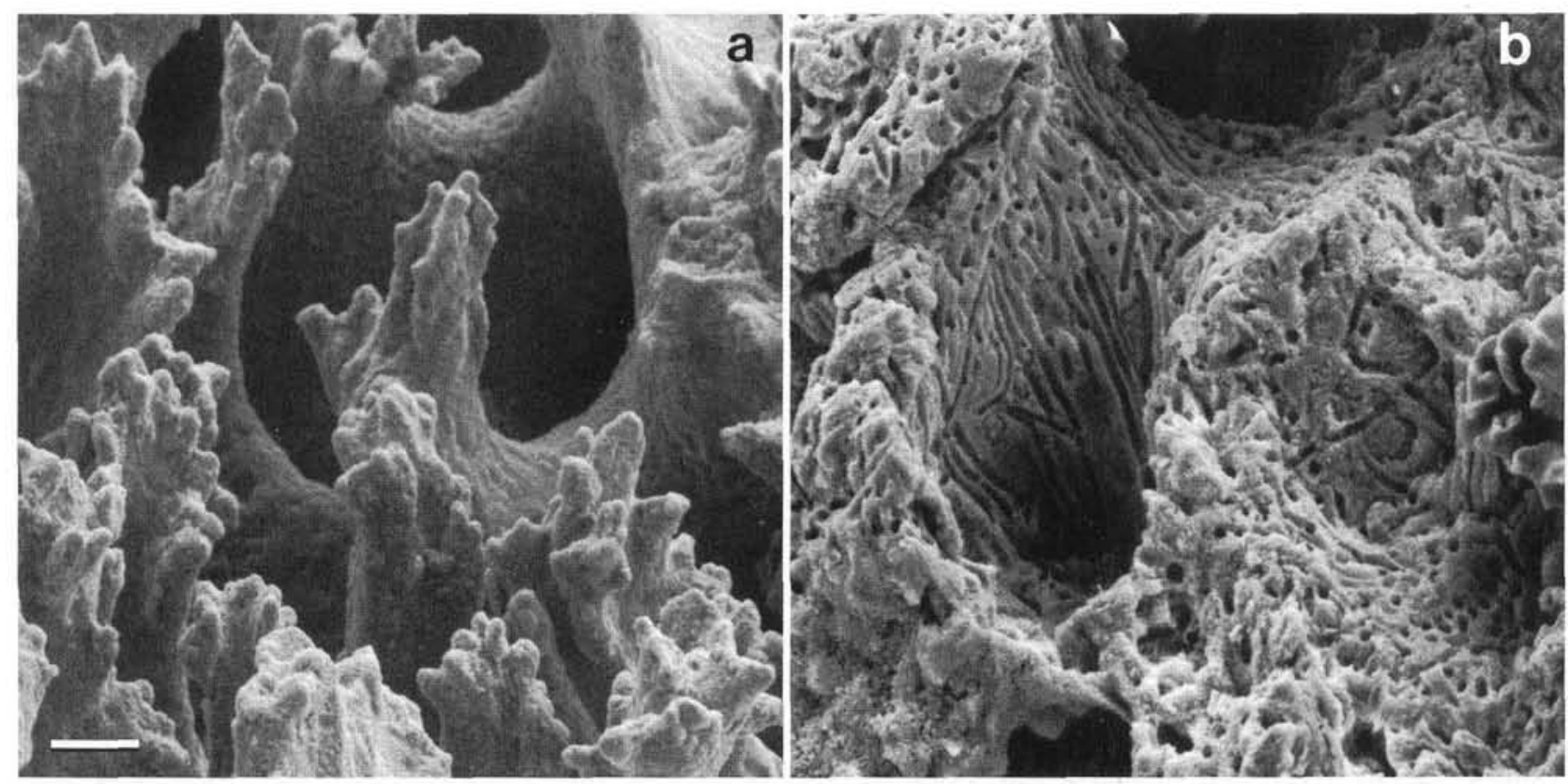

Fig. 3. Surface of the Porites lobata skeleton. (a) Newly formed skeleton exposed by removal of the polyps by sodium hypochlorite (Clorox). Although the interior of the skeleton is perforated by Ostreobium quekettii, the surface remains intact. (b) Surface of dead areas of the same coral that were attacked externally by various endoliths, also cleaned with sodium hypochlorite. Note the dense meshwork of borings that riddle the skeleton surface. Same magnification; scale bar $=10 \mu \mathrm{m}$ 


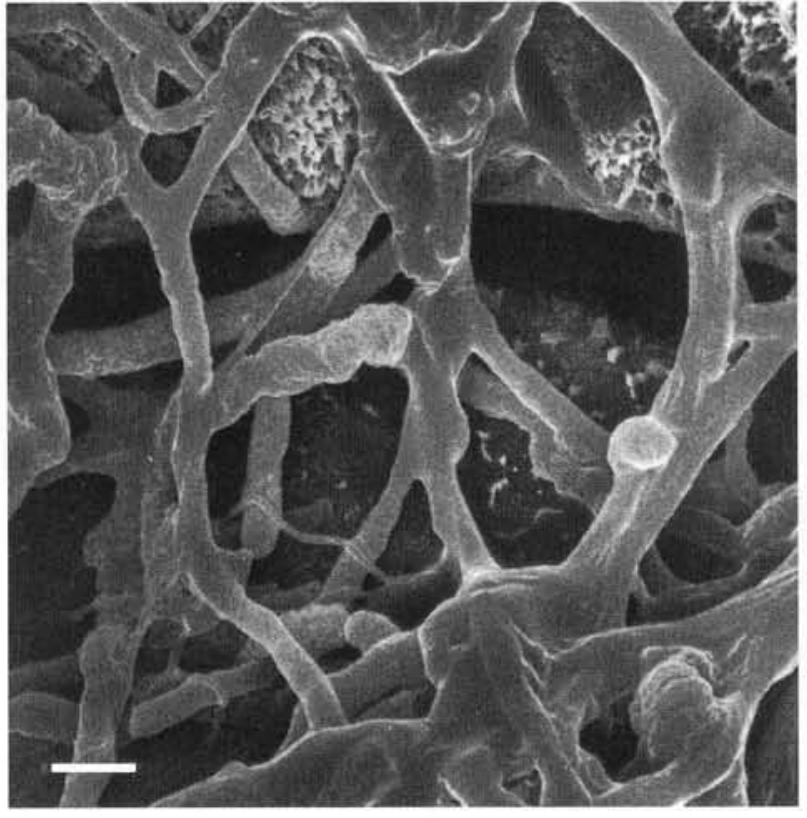

Fig. 4. Resin casts of a dense tunnel network of Ostreobium quekettii within the green band in Porites lobata. Note the variable size, shape and branching pattern of this alga. Thin filaments to the lower left are casts of endolithic fungal hyphae. Scale bar $=10 \mu \mathrm{m}$

live corals. Resin-cast preparations cut perpendicular to the surface of the corallum revealed that the density of this microflora decreased rapidly with increasing distance from the surface and remained essentially restricted to the upper (less than $1 \mathrm{~mm}$ ) surface layer of the dead skeleton (Fig. 5). In the absence of intensive grazing, the surfaces of dead coral skeleton became overgrown by a dense epilithic turf of coccoid and filamentous cyanobacteria belonging to the genera Entophysalis, Calothrix, Spirulina, and Phormidium. When the epilithic algal turf was removed by sodium hypochlorite (Clorox bleach), the surface of the dead coral skeleton revealed numerous perforations (Fig. 3b), showing a picture quite different from that of similarly treated colonies of live corals (Fig. 3a). Up to 3500 perforations $\mathrm{mm}^{-2}$ with a diameter of 5 to $6 \mu \mathrm{m}$ were counted in such preparations.

The species composition of euendolithic microflora developing on dead and denuded coral skeletons was similar to that encountered in other carbonate substrates within the same general environment, such as shell fragments, carbonate sediment grains, and coastal limestone. It was comprised most commonly of the cyanobacteria Mastigocoleus testarum Lagerheim and Plectonema terebrans (Fig. 6) (see Golubic \& Le Campion-Alsumard 1973, Le Campion-Alsumard 1975).

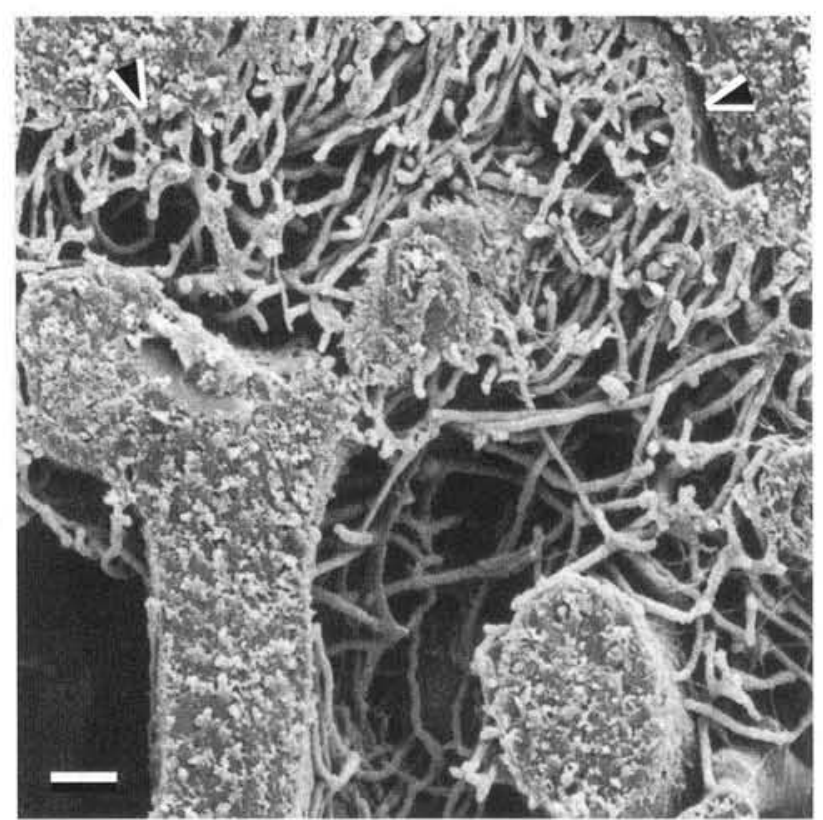

Fig. 5. Resin-cast of the surface region (arrowheads) of a dead and denuded Porites lobata skeleton in sagittal section. High density of borings at the surface (cf. Fig. 3b) diminishes rapidly toward the interior of the skeleton. Alveolar spaces are filled with resin in this preparation. Scale bar $=50 \mu \mathrm{m}$

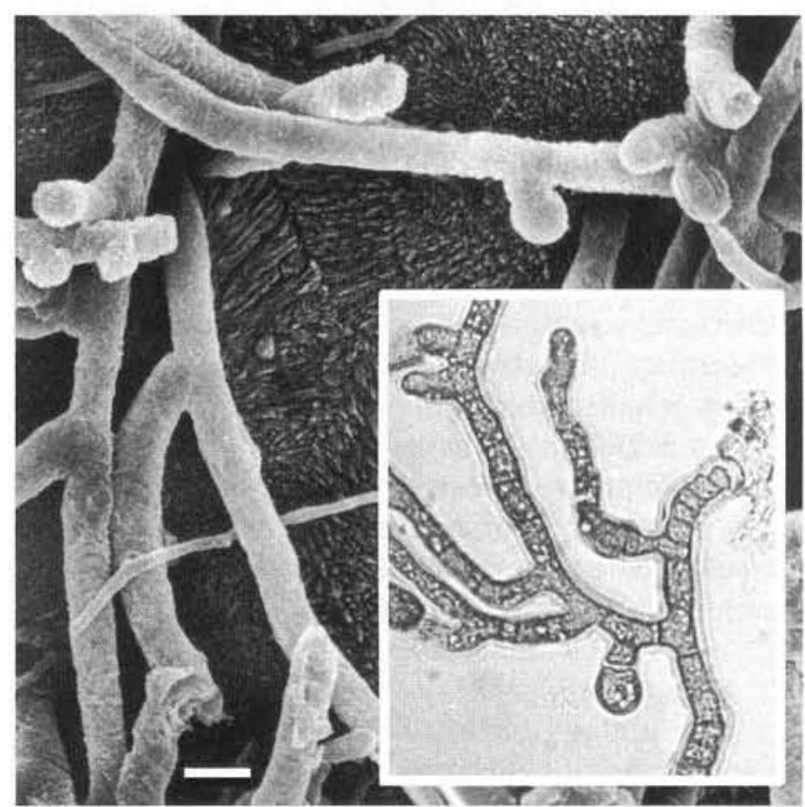

Fig. 6. Resin casts of Mastigocoleus testarum tunnels in the skeleton of dead Porites lobata. Short lateral branches with swollen ends reveal the positions of terminal heterocysts. The narrow cast belongs to Plectonema terebrans. Inset: M. testarum extracted by dissolution of the coral skeleton. Same magnification; scale bar $=10 \mu \mathrm{m}$ 
In order to determine the sequence of events following death and denudation of corals, cleaned pieces of coral skeleton were attached to coral heads in the lagoon and exposed to endolith colonization. Blocks of clear calcite spar were also exposed for rapid surveying. The exposed substrates were sampled and analyzed at increasing time intervals of up to 3 mo over a period of $2 \mathrm{yr}$. The colonization proceeded in several successional stages. The first borings on freshly exposed skeleton surfaces occurred within $20 \mathrm{~d}$ of exposure, and were carried out by the septate green endolithic alga Phaeophila dendroides (Crouan) Batters. Over the following 7 mo of exposure, this pioneer microflora was completely replaced by the cyanobacteria Mastigocoleus testarum and Plectonema terebrans. After an exposure of $1 \mathrm{yr}$, Ostreobium quekettii was present, and became gradually dominant by the end of the second year of exposure.

The coral colony responds to damage in several ways. Minor damage, accompanied by a reversible loss of zooxanthellae (bleaching) where the polyps remain active, may result in temporary decrease in coral growth rates (Risk \& Pearce 1992) without leaving external scars. Damage that results in death of polyps but is limited in extent is 'healed' by neighboring polyps which bend over the damaged area and cover it. Larger areas of damage and denudation of coral tissue usually appear as depressions surrounded by intact coral tissue that continues to grow around them. We observed a dense wall of compact carbonate deposited by the polyps bordering the damaged area and separating the damaged depression from the healthy tissue.

Organic production by epilithic and endolithic microorganisms on dead corals is an important component of the food chain on coral reefs. Grazing by sea urchins and scarid fish also removes a layer of carbonate substrate, thereby contributing to bioerosion. The grazing activity, which depends on microbial production, intensified in the course of the $2 \mathrm{yr}$ of exposure. The rates of these activities, which are orders of magnitude above those of bioerosion in live corals, are the subject of a separate publication (Chazottes et al. in press).

\section{DISCUSSION}

Highsmith (1981) summarized the published information on endoliths in hermatypic corals and confronted several contradictions present in the literature. The evidence concerning some of the unresolved problems, such as the specificity of endolith colonization, the changes in species composition following death of corals, and the origins and significance of color banding can now be reassessed in the light of new observations.

The difference between endolith assemblages inhabiting skeletons of live vs dead corals has been known for a long time, but has not been explained. Lukas (1973) documented the ubiquitous nature of Ostreobium quekettii infestation in corals, occurring at $100 \%$ frequency in Atlantic and Pacific corals $(\mathrm{n}=$ $156)$. Almost all $(>97.5 \%)$ of the hermatypic corals studied contained green bands visible with the unaided eye. Other endolithic microorganisms that are occasionally observed within the corallum of live corals, such as Plectonema terebrans, conchocelis stages of bangiacean rhodophytes, and fungi, play a subordinate role (Laborel \& Le Campion-Alsumard 1979). Odum \& Odum (1955) speculated on the possible symbiotic relationship between $O$. quekettii and live corals, and Delvoye (1992) on the possible exchange of nutrients between them. However, $O$. quekettii is not limited to growth in live corals. Rather, it is one of the most common endoliths in deeper subtidal ranges in any carbonate substrate (Le CampionAlsumard et al. 1982). The present study has shown that $O$. quekettii eventually becomes dominant in dead coral skeletons as well, following disturbance caused by the death of the coral, and a series of successive endolith populations. Thus, the relationship between $O$. quekettii and its coral host is not one of obligatory dependence.

Instead, we suggest that the specific composition of endoliths in corals is a result of a selection of species which can cope with accretion rates of the coral skeleton. The dynamics of live, actively accreting skeletons represents a special challenge for endoliths, a sort of 'moving target' which limits the colonization to a few specialists. Both the protection afforded by the polyp layers and the rapid growth of coral skeleton select against colonization by most euendoliths, in favor of a few fast-boring, oligophotic taxa with a positive phototropic response, i.e. with the same growth orientation as the coral host. Other endoliths that bore in a direction opposite to coral accretion (Fig. 4), even if successfully colonized, would soon be sealed off, buried and deprived of light by new skeletal carbonate.

In addition to Ostreobium quekettii, as illustrated by Lukas (1974, Fig. 1), positive phototropic growth is exhibited by conchocelis stages of bangiacean rhodophytes and, less clearly, by Plectonema terebrans. All 3 are found in skeletons of live corals. In contrast, dead and denuded surfaces of corals (like non-living carbonate substrate) are colonized by negatively phototropic taxa. The difference in strategy and pattern of endolith boring behavior by these types is expressed in their opposing filament density gradients found in the substrate. Borings in live corals exhibit a downward 


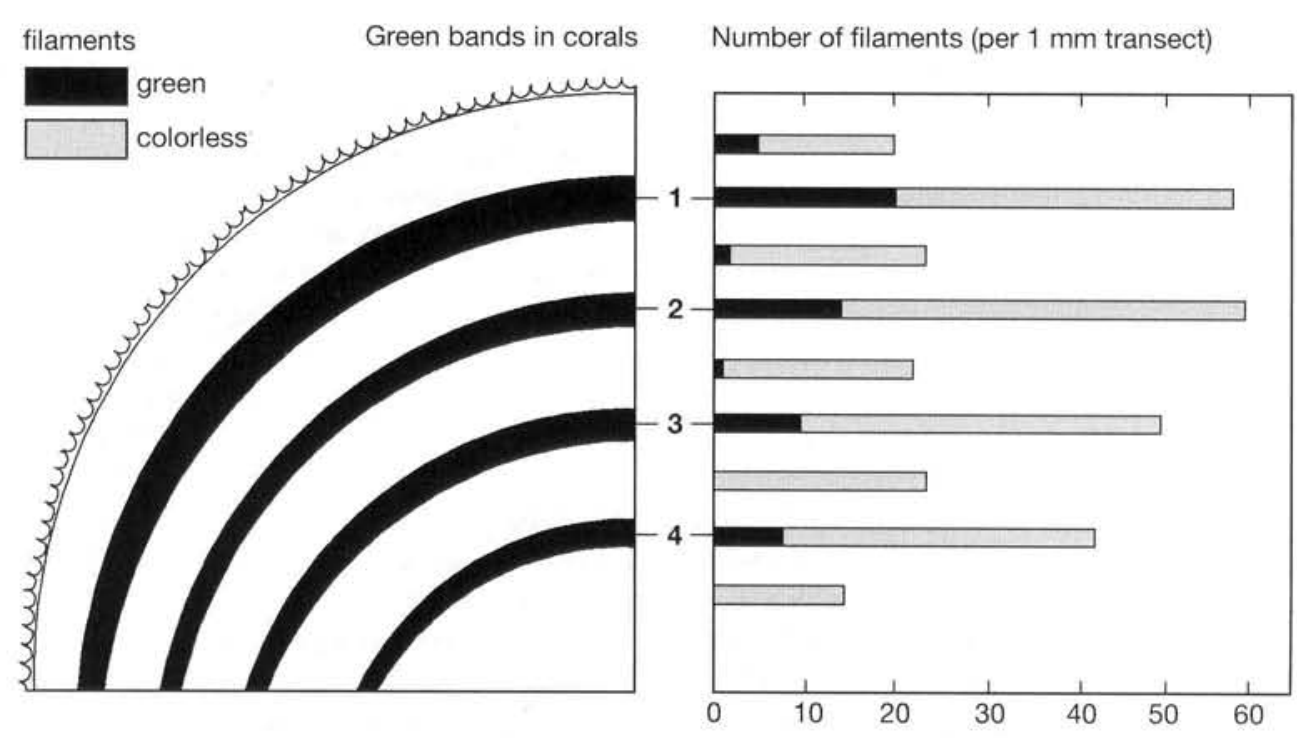

Fig. 7. Distribution of Ostreobium quekettii in corals. Left: Idealized sagittal section through a coral head with 4 green bands alternating with 5 colorless bands. Right: Corresponding distribution of pigmented and pigment-free O. quekettii filaments in the bands shown to the left. Data assembled by Lukas (1973) from a large number of coral heads have been pooled in constructing the histogram. Green banding corresponds to a higher total number of filaments per transect, and a higher proportion of those containing chloroplasts

density increase, culminating in banding, whereas those in dead corals are densest at the surface and show a downward density decrease (Fig. 5). The difference in boring strategy is also evident from the striking difference in appearance of the corallum surface between live and dead corals (Fig. 3a vs b).

Another problem related to the dynamics of coral growth is the presence of multiple colored bands within their skeletons. Lukas (1979) reported that only the outer band contains live and growing algae, while the inner bands record past growth concentrations. Highsmith (1981) interpreted the occurrence of green banding as periods of improved algal growth analogous to algal blooms. He suggested that these may reflect seasonal growth or even seasonal recruitment of algae. In view of our observations of the intact surfaces of live and growing corallum (Fig. 3a), seasonal recruitment should be ruled out.

Both Lukas and Highsmith observed that the uppermost green band is usually located parallel with and several $\mathrm{mm}$ beneath the surface, with a white band above which separates it from the zone inhabited by coral polyps. Highsmith concluded that the white band immediately beneath the growing coral front is caused by photoinhibition of algal growth. Lukas interpreted the white band between the polyp zone and the green band as a lag between coral growth and the growth and branching maximum of the alga. Both Highsmith's and Lukas' conclusions are consistent with the findings that the green bands are generally closer to the surface of the corallum in deeper waters (Lukas 1973, Part 3, Fig. 6; Highsmith 1981, Fig. 5; Delvoye 1992, Fig. 3), where light intensity is lower, but where coral growth rates are slower as well (Highsmith 1979).

Lukas (1973) has documented the presence of Ostreobium quekettii filaments in white as well as green bands. Lukas also found no green banding in rapidly growing corals, although these too contained $O$. quekettii filaments, but at lower densities. Quantitative data on filament distribution in live corals provided by Lukas (1973) are plotted here in Fig. 7. The pattern which emerges is that the colored bands contain a higher total density of filaments as well as a higher density of pigment-containing filaments. Apparently, the cytoskeleton of this siphonal alga is able to displace a portion of the chloroplasts upward during periods of fast growth. These become trapped, however, in the side-branches developed during periods of slow coral growth. Consequently, white bands have on the average $60 \%$ fewer total filaments but $90 \%$ fewer pigmented filaments than the overlying green bands. The top white band, however, where evacuation of chloroplasts does not take place, contains a lower total number of filaments, but the proportion of green ones $(24 \%)$ is in the same range as that in the green bands (17 to $34 \%$, average $23.5 \%$ ).

From her observations, Lukas concluded that the interior colored bands reflect periods of slower coral growth during which the endolith has increased in density. Our observations on Porites sp. with irregular, 
bumpy growth point in the same direction. The regions along the band with higher filament and pigment densities are invariably located closer to the accreting coral front, i.e. they correlate with the slower-growing depressions located between faster-growing protuberances of the coral. This finding is consistent with the observed shallower position of the green band on the slopes of coral heads. The effect is enhanced whenever coral growth is inhibited by damage. In such cases the green band intensifies in color and 'catches up' with the coral growth moving closer to the surface of the corallum (see also Lukas 1973, Part 3, Fig. 9). Surface concentrations of Ostreobium quekettii on damaged and denuded areas of corals, together with the findings of $O$. quekettii filaments in healthy corals at the very tips of newly deposited corallum spines, clearly rule out photoinhibition as the explanation for the white band. Photoinhibition of $O$. quekettii in corals could not be confirmed in the most recent experimental studies by Shashar \& Stambler (1992). Nevertheless, the ecological relationship of this oligophotic species to light as a determinant of distribution should not be dismissed.

The dominance of Ostreobium quekettii does not extend into the very shallow ranges, where it is usually outcompeted by Phaeophila dendroides. O. quekettii at these shallower depths is prevalent only on the lower shaded surfaces of rocks, suggesting that this organism retains a competitive edge at low light intensities. This observation is consistent with the success of $O$. quekettii in corals, where it uses light after it has been filtered by layers of zooxanthellae, and by its depth distribution to $275 \mathrm{~m}$ (S. Golubic unpubl.). Several independent observations support the notion that the green $O$. quekettii bands (or pink conchocelis bands) result from algal accumulation during retarded coral growth, but they do not rule out the possibility that seasonally enhanced algal growth contributes to band formation, as suggested by Highsmith (1981).

The possibility that Ostreobium quekettii bands represent a separate internal clock (Risk et al. 1987) reflecting either algal seasonality or periods of slower coral growth, or a combination of both, has ecological implications. Seasonal growth of corals, as reflected in skeletal density banding, has been amply documented in the literature (reviewed by Barnes \& Lough 1989, Dunbar \& Cole 1993); however, the seasonality of $O$. quekettii remains unknown. Attempts to correlate endolith bands with corallum density bands showed no consistency. Some authors reported the algal bands to correlate with low-density (Bak \& Laane 1987, Risk et al. 1987), others with high-density growth bands (Macintyre \& Smith 1974, Pätzold 1988). The inconsistencies in the X-radiographic sclerochronologic record in Porites have also recently been recognized and to some extent explained by the intrinsic complexity of the growth rhythm and upward displacement of polyps in this genus (Barnes \& Lough 1993).

We suggest that the removal of carbonate from the corallum by endoliths may have a significant effect on its density pattern, and may further help to explain the inconsistencies in the sclerochronologic record. Density of the corallum within the green band may be substantially reduced (Fig. 4), on average by $8 \%$ (corrected for the substrate porosity from a measured $12 \% \mathrm{CaCO}_{3}$ removal) (Highsmith 1981). This value is quite close to the $9 \%$ average annual density variation cited for Porites in the Great Barrier Reef which provided a clear X-radiographic banding pattern (Barnes \& Lough 1993).

As in other complex ecosystems, environmental changes in coral reefs are reflected and recorded in organismal growth patterns and rhythms. Minor changes can shift the balance between constructive and destructive processes within corals, leaving subtle signatures in the record, such as the Ostreobium quekettii bands. Major changes resulting in death of corals cause dramatic changes in endolith species composition. Denudation of the corallum following coral death fosters settlement of opportunistic species (e.g. Phaeophila dendroides) that occupy and penetrate newly available substrates. These early colonizers, however, are generally short-lived, giving way to a series of successional replacements, with an ultimate prevalence of species that are competitive under relatively stable, long-term conditions - such as $O$. quekettii.

Acknowledgements. This work was made possible by the support of a grant from INSU/ORSTOM (AIP 'Récifs coralliens'), by the National Associate Professor Program of the University of Aix-Marseille, and by grant PICS 77, FrenchAustralian Cooperation. We thank K.-P. Vogel, G. Radtke and W. E. Kiene, University of Frankfurt/Main, and J. C. Lang, University of Texas, Austin, for providing opportunities for comparisons with Caribbean corals.

\section{LITERATURE CITED}

Bak, R. P. M. (1976). The growth of coral colonies and the importance of crustose coralline algae and burrowing sponges in relation with carbonate accumulation. Neth. J. Sea Res. 10: 285-337

Bak, R. P. M., Laane, W. P. M. (1987). Annual black bands in skeletons of reef corals (Scleractinia). Mar. Ecol. Prog. Ser. 38: $169-175$

Barnes, D. J., Lough, J. M. (1989). The nature of skeletal density banding in scleractinian corals: fine banding and seasonal patterns. J. exp. mar. Biol. Ecol. 126: 119-134

Barnes, D. J., Lough, J. M. (1993). On the nature and causes of density banding in massive coral skeletons. J. exp. mar. Biol. Ecol. 167: 91-108 
Chazottes, V., Le Campion-Alsumard, T., Peyrot-Clausade, M. (in press). Bioerosion rates on coral reefs: interaction between macroborers, microborers and grazers (Moorea, French Polynesia). Palaeogeogr. Palaeoclimatol. Palaeoecol.

Delvoye, L. (1992). Endolithic algae in living stony corals: algal concentrations under influence of depth-dependent light conditions and coral tissue fluorescence in Agaricia agaricites (L.) (Scleractinia, Anthozoa). Stud. nat. Hist. Caribbean Region 71: 27-41

Duerden, J. E. (1902). Boring algae as agents in the disintegration of corals. Bull. Am. Mus. nat. Hist. 16: 323-332

Dunbar, R. B., Cole, J. E. (1993). Coral records of oceanatmosphere variability. NOAA Clim. Global Change Program Spec. Rep. 10: I-VI, 1-38

Gattuso, J.-P., Pichon, M., Delesalle, B., Frankignoulle, M. (1993), Community metabolism and air-sea $\mathrm{CO}_{2}$ fluxes in a coral reef ecosystem (Moorea, French Polynesia). Mar. Ecol. Prog. Ser. 96: 259-267

Golubic, S., Brent, G., Le Campion, T. (1970). Scanning electron microscopy of endolithic algae and fungi using a multipurpose casting-embedding technique. Lethaia 3: 203-209

Golubic, S., Friedmann, I., Schneider, J. (1981). The lithobiontic ecological niche, with special reference to microorganisms. J. sedim. Petrol. 51: 475-478

Golubic, S., Le Campion-Alsumard, T. (1973). Boring behavior of marine blue-green algae Mastigocoleus testarum Lagerheim and Kyrtuthrix dalmatica Ercegovic, as a taxonomic character. Schweiz. Z. Hydrol. 35: 157-161

Highsmith, R. C. (1979). Coral growth rates and environmental control of density banding. J. exp. mar. Biol. Ecol. 37: 105-125

Highsmith, R. C. (1981). Lime-boring algae in hermatypic coral skeleton. J, exp. mar. Biol. Ecol. 55: 267-281

Hubbard, D. K., Miller, A. I., Scaturo, D. (1990). Production and cycling of calcium carbonate in a shelf-edge reef system (St. Croix, U.S. Virgin Islands): applications to the nature of reef systems in the fossil record. J. sedim. Petrol. 60: $335-360$

Hutchings, P. A. (1986). Biological destruction of coral reefs. A review. Coral Reefs 4: 239-252

Hutchings, P. A., Peyrot-Clausade, M. (1988). Macroinfaunal boring communities of Porites, a biogeographical comparison. Proc. 6th Int. Coral Reef Symp. 3: 263-267

Kendrick, B., Risk, M. J., Michaelides, J., Bergman, K. (1982). Amphibious microborers: bioeroding fungi isolated from live corals. Bull. mar. Sci. 32: 862-867

Kiene, W. E. (1985). Biological destruction of experimental coral substrates at Lizard Island, Great Barrier Reef, Australia. Proc. 5th Int. Coral Reef Symp. 5: 339-344

Kiene, W. E. (1988). A model of bioerosion on the Great Barrier Reef. Proc. 5th Int. Coral Reef Symp. 3: 449-454

Kiene, W. E., Hutchings, P. A. (1994). Bioerosion experiments at Lizard Island, Great Barrier Reef. Coral Reefs 13: 91-98

Laborel, J., Le Campion-Alsumard, T. (1979). Infestation massive du squelette de coraux vivants par des Rhodophycées de type Conchocelis. C.r. Acad. Sci., Paris 288: 1575-1577

Le Campion-Alsumard, T. (1975). Etude expérimentale de la colonisation d'éclats de calcite par les Cyanophycées endolithes marines. Cah. Biol. mar. 16: 177-185

Le Campion-Alsumard, T., Campbell, S. E., Golubic, S. (1982). Endoliths and the depth of the photic zone-discussion. J. sedim. Petrol. 52: 1333-1334

Le Campion-Alsumard, T., Golubic, S., Priess, K. (1995). Fungi in corals: symbiosis or disease? Interaction between polyps and fungi causes pearl-like skeleton biomineraliza- tion. Mar. Ecol. Prog. Ser. 117: 137-147

Lukas, K. J. (1969). An investigation of the filamentous, endolithic algae in shallow-water corals from Bermuda. In: Ginsburg, R. N., Garrett, P. (eds.) Reports of research the 1968 seminar on organism-sediment interrelationships. Bermuda Biol. Stn Res. Spec. Publ. 2: 145-152

Lukas, K. J. (1973). Taxonomy and ecology of the endolithic microflora of reef corals with a review of the literature on endolithic microphytes. Ph.D. thesis, University of Rhode Island, Kingston

Lukas, K. J. (1974). Two species of the chlorophyte genus Ostreobium from skeletons of Atlantic and Caribbean reef corals. J. Phycol. 10: 331-335

Lukas, K. J. (1979). The effects of marine microphytes on carbonate substrata. Scanning Electron Microsc. 11: 447-456

Macintyre, I. G., Smith, S. V. (1974). X-radiographic studies of skeletal development in coral colonies. Proc. 2nd Int. Coral Reef Symp. 2: 277-287

Neumann, A. C. (1968). Biological erosion of limestone coasts. In: Fairbridge, R. W. (ed.) Encyclopedia of geomorphology. Reinhold Book Corp., New York, p. 75-81

Newhouse, J. (1954). Notes on Myxophyta of Raroia. Atoll Res. Bull. 33: 45-58

Odum, H. T., Odum, E. P. (1955). Trophic structure and productivity of a windward coral reef community. Ecol. Monogr, 25: 291-320

Pätzold, J. (1988). The effect of early lithification on the stable oxygen and carbon isotopic composition of Porites lobata. Proc. 6th Int. Coral Reef Symp. 3: 559-564

Payri, C. E. (1987), Variabilité spatiale et temporelle de la communauté des macrophytes des récifs coralliens de Moorea (Polynésie française). Contribution des algues au métabolisme du carbone de l'écosystème récifal. $\mathrm{Ph} . \mathrm{D}$. thesis, Université Sciences et Techniques du Languedoc, Montpellier

Peyrot-Clausade, M., Hutchings, P. A., Richard, G. (1992). The distribution and successional patterns of macroborers in marine Porites at different stages of degradation on the barrier reef, Tiahura, Moorea, French Polynesia. Coral Reefs 11: 161-166

Ranson, G. (1955). Observations sur les principaux agents de la dissolution du calcaire sous-marin dans la zone côtière des îles coralliennes de l'Archipel des Tuamotu. C.r. Acad. Sci., Paris 240: 806-808; $1007-1009$

Ranson, G. (1956), Observations sur les facteurs biologiques de la dissolution du calcaire d'origine récifale dans les Tuamotu. Proc. 8th Pacific Sci. Cong. IIIA: 979-988

Risk, M. J., Pagani, S. E., Elias, R. J. (1987). Another internal clock: preliminary estimates of growth rates based on cycles of algal boring activity. Palaios 2: 323-331

Risk, M. J., Pearce, T. H. (1992). Interference imaging of daily growth bands in massive corals. Nature (London) 358: $572-573$

Schneider, J., Torunski, H. (1983). Biokarst on limestone coasts, morphogenesis, and sediment production. P.S.Z.N. I: Mar. Ecol. 4: 45-63

Schroeder, J. H. (1972). Calcified filaments of an endolithic alga in recent Bermuda reefs. Neues Jahrb. Geol. Paleontol. Monatsh. 1: 16-33

Shashar, N., Stambler, N. (1992). Endolithic algae within corals - life in an extreme environment. J. exp. mar. Biol. Ecol. 163: 277-286

Weber van Bosse, A. (1932). Algues. Résultats scientifiques du voyage aux Indes Orientales Néerlandaises de LL. AA. RR. le Prince et la Princesse Léopold de Belgique. Mém. Mus. r. Hist. nat. Belg. (Hors Sér.) 6: 1-28 